\title{
Penetration Sites and Migratory Routes of Angiostrongylus costaricensis in the Experimental Intermediate Host (Sarasinula marginata)
}

\author{
Cristiane LGF Mendonça, Omar S Carvalho, Ester M Mota*, \\ Marcelo Pelajo-Machado*, Luzia FG Caputo*, Henrique L Lenzi*/+
}

\begin{abstract}
Laboratório de Helmintoses Intestinais, Centro de Pesquisas René Rachou-Fiocruz, Caixa Postal 1743, 30190-002 Belo Horizonte, MG, Brasil *Departamento de Patologia, Instituto Oswaldo Cruz, Av. Brasil 4365, 21045-900 Rio de Janeiro, RJ, Brasil
\end{abstract}

The intermediate hosts of Angiostrongylus costaricensis are terrestrian molluscs, mostly of the family Veronicellidae. The present work aimed at clarifying more accurately the sites of penetration and the migratory routes of A. costaricensis in the tissue slugs and at verifying the pattern of the perilarval reaction at different times of infection. Slugs were individually infected with 5,000 $L_{1}$, and killed from 30 min to 30 days after infection. From 30 min up to $2 \mathrm{hr}$ after infection, $L_{1}$ were found within the lumen of different segments of the digestive tube having their number diminished in more advanced times after exposition until complete disappearance. After 30 min of exposition, percutaneous infection occurred, simultaneously to oral infection. Perilarval reaction was observed from $2 \mathrm{hr}$ of infection around larvae in fibromuscular layer, appearing later (after $6 \mathrm{hr}$ ) around larvae located in the viscera. A pre-granulomatous reaction was characterized by gradative concentration of amebocytes around larvae, evolving two well-organized granulomas. In this work we confirmed the simultaneous occurrence of oral and percutaneous infections. Perilarval reaction, when very well developed, defined typical granulomatous structure, including epithelioid cell transformation. The infection also caused a systemic mobilization of amebocytes and provoked amebocyte-endothelium interactions.

Key words: Angiostrongylus costaricensis - Sarasinula marginata - intermediate host - migratory routes amebocytes - granuloma

The intermediate hosts of Angiostrongylus costaricensis Morera \& Céspedes 1971, the aetiological agent of abdominal angiostrongyliasis (Morera \& Céspedes 1971) are terrestrial molluscs, mostly of the family Veronicellidae: Costa Rica (Morera \& Ash 1970), Ecuador (Morera et al. 1983), Honduras (Kaminsky et al. 1987, Morera et al. 1988), Nicaragua (Duarte et al. 1992) and Brazil (Graeff-Teixeira et al. 1989, Rambo at al. 1997). Molluscs from other groups, like Limax maximus, may play an important role as intermediate hosts for the parasite in some regions (GraeffTeixeira et al. 1993). Morera (1973), describing for the first time the parasite's life cycle within the intermediate host, reported ingestion of $\mathrm{L}_{1}$ as a way of infection (oral infection). Thiengo (1996) showed the passage of first stage larvae across the

\footnotetext{
Work partially supported by Papes 383 (Fiocruz).

${ }^{+}$Corresponding author. Fax:+55-21-590.3495. E-mail: hlenzi@gene.dbbm.fiocruz

Received 9 June 1998

Accepted 2 March 1999
}

tegument of Sarasinula marginata Semper, 1885 (tegumental or percutaneous infection).

Conejo and Morera (1988) studied the perilarval reaction in slugs of different ages, either in primary A. costaricensis infections or reinfections, showing for the first time in the literature an amebocytic reaction of the intermediate host to this parasite.

The present work aimed at clarifying more accurately the sites of penetration and the migratory routes of A. costaricensis in the slugs and at displaying the characteristic of the perilarval reaction at different times of infection, specifying its cellular composition.

\section{MATERIALS AND METHODS}

Twenty five slugs of $S$. marginata were individually infected with 5,000 larvae $\left(\mathrm{L}_{1}\right)$, killed at $30 \mathrm{~min}, 1,2,4,6,8 \mathrm{hr}$, and 1, 2, 4, 5, 6, 8, 10, 11, $12,14,15,16,20,21,22,25,26,28$ and 30 days after infection, and fixed in Carson's FormalinMillonig (Carson et al. 1973). Serial cross-sections were stained with Hematoxylin-Eosin (HE), PASAlcian Blue ph 1.0 and 2.5, PhosphomolybdicPicrosirius Red (PMA-PS) (Dolber \& Spach 1993) 
and examined by brightfield and confocal laser microscopes (LSM-410, Zeiss) using transmission and reflected modes. For documentation, selected slides were analyzed in LSM-410 and in Photomicroscope III (Zeiss) and the images were transferred from the microscopes to Microsoft Imager ${ }^{\mathrm{TM}}$ and Corel Draw $6.0^{\mathrm{TM}}$ for final adjustments of contrast, brightness and gamma-correction, and then printed in a Codonics ${ }^{\text {TM }}$ NP1600 printer.

\section{RESULTS}

Oral infection - From 30 min to $2 \mathrm{hr}$ many larvae $\mathrm{L}_{1}$ were found inside the lumen of different segments of the digestive tract (buccal bulb, esophagus, crop, stomach, intestine and digestive gland) (Fig. 1). The number of larvae diminished substantially at subsequent times and disappeared at these sites, two days after infection.

The penetration through the epithelium of the digestive apparatus occurred in three different steps: (1) adhesion of $\mathrm{L}_{1}$ to epithelium cells, causing a depression of the epithelium and thinning the cuticular layer (Fig. 2); (2) trans-epithelial migration until reaching the basal membrane (Fig. 3); (3) transposition of basal membrane and invasion of the connective subepithelial layer (Figs 3,4). Afterward, larvae could be detected within different organs like salivary, pedal, penial, and albume glands, penis, sheath of penis, ovariotestis, prostate, cerebral ganglia, copulation purse, heart and kidney. Sometimes, larvae were found in the pericardiac coeloma.

Cutaneous via - Percutaneous infection was found to occur simultaneously to the oral infection, from 30 min onward, after exposition. Large amount of larvae was found in the ventral surface and foot, and the preferential site of external penetration appeared to be the excretory ducts of the mucous glands (Figs 7, 8, 9). After penetration of the epidermis or the ductal epithelium, the larvae remained within the fibromuscular layer (Figs 9, $12)$, where they were gradually surrounded by amebocytic reaction (Figs 9, 12, 14, 15, 18, 19).

Perilarval reaction - It was observed $2 \mathrm{hr}$ after infection, around larvae located in the fibromuscular layer of the body, starting lately (6 hr) around larvae trapped within the viscera (Fig. 13). The reaction consisted exclusively of amebocytes (hemocytes or celomocytes) which initially formed an involving cell monolayer around the larvae (Fig. 11) with formation of subsequent layers (Figs 10, $12,14)$, characterizing pre-granulomatous reactions (Fig. 14). These lesions culminated on the 4th day of infection as organized granulomas, forming two well defined strata: (1) the inner stratum, composed of several concentric layers of amebocytes, with or without epithelioid transformation, and (2) the outer stratum, formed by flattened or fibroblasticlike cells, which constituted a pseudocapsule (Fig. 18). According to the time of infection and the site of reaction, there were: (a) intense and scattered infiltrate around the larvae without organoid aspect (Fig. 13); (b) clusters of spherical amebocytes surrounding the larvae within vessels (pre-granulomatous reaction) (Fig. 16); (c) fibroblastic-like amebocytes (Fig. 17); and (d) vacuolization of amebocytes (Figs 19, 23). There was no evidence of collagen fibers permeating the amebocytic infiltrate even in the 30 days-granulomas (Figs 15, 22). After 30 days of infection the granulomas were seen mostly within vessel cavities (Fig. 20-22) producing emboli and causing vascular ectasia (Figs 20, 21). Larvae always appeared very well preserved, independently of the developmental stage: $\mathrm{L}_{1}$ (Fig. 12), $\mathrm{L}_{2}$ (Fig. 18) and $\mathrm{L}_{3}$ (Figs 19, 23). Degenerating parasites were not found during all the time of experiment.

Systemic intravascular reaction - Concomitantly with the intensification of the perilarval reaction, occurred also a significant increase in the number of circulating amebocytes not directly related to the presence of intravascular larvae. These amebocytes showed adhesion between them and margination due to adherence to endothelium (Fig. 24). Sometimes, in small vessels, amebocytes were adhered to the endothelial region faced to contiguous perilarval reaction (Fig. 14).

\section{DISCUSSION}

In this work we confirmed the simultaneous occurrence of oral and tegumental or percutaneous infection by $\mathrm{L}_{1} A$. costaricensis in intermediate host, $S$. marginata. We displayed the mode and the sites of $\mathrm{L}_{1}$ penetration, the involvement of several viscera in the routes of parasite migration, and characterized the patterns of perilarval (pre-granuloma and granuloma) and systemic (hemocytosis) amebocytic reactions.

The penetration of $\mathrm{L}_{1}$ across the molluscan epithelium of the digestive tract reproduced the same events observed in the penetration of $\mathrm{L}_{3}$ across the intestinal epithelium of murine (definitive) host (EM Mota \& HL Lenzi manus. in prep.). In both hosts, the penetration process happened rapidly, without induction of any inflammatory reaction, and appeared to partially depend on unknown proteolytic mechanisms. The $\mathrm{L}_{1}$ penetration occurred at different levels of the molluscan digestive tract, showing no preference to specific segments.

Our observations indicated that, in the tegumental infection, $\mathrm{L}_{1}$ gained entry into the mollusc preferentially through the excretory ducts of the mucous glands, where the epithelium is thinner 
than the epidermal cells. These ducts drain the secretion of several individual mucous cells rich in carboxylated and non-sulfated proteoglycans (hyaluronic acid?) and neutral glycoproteins. We do
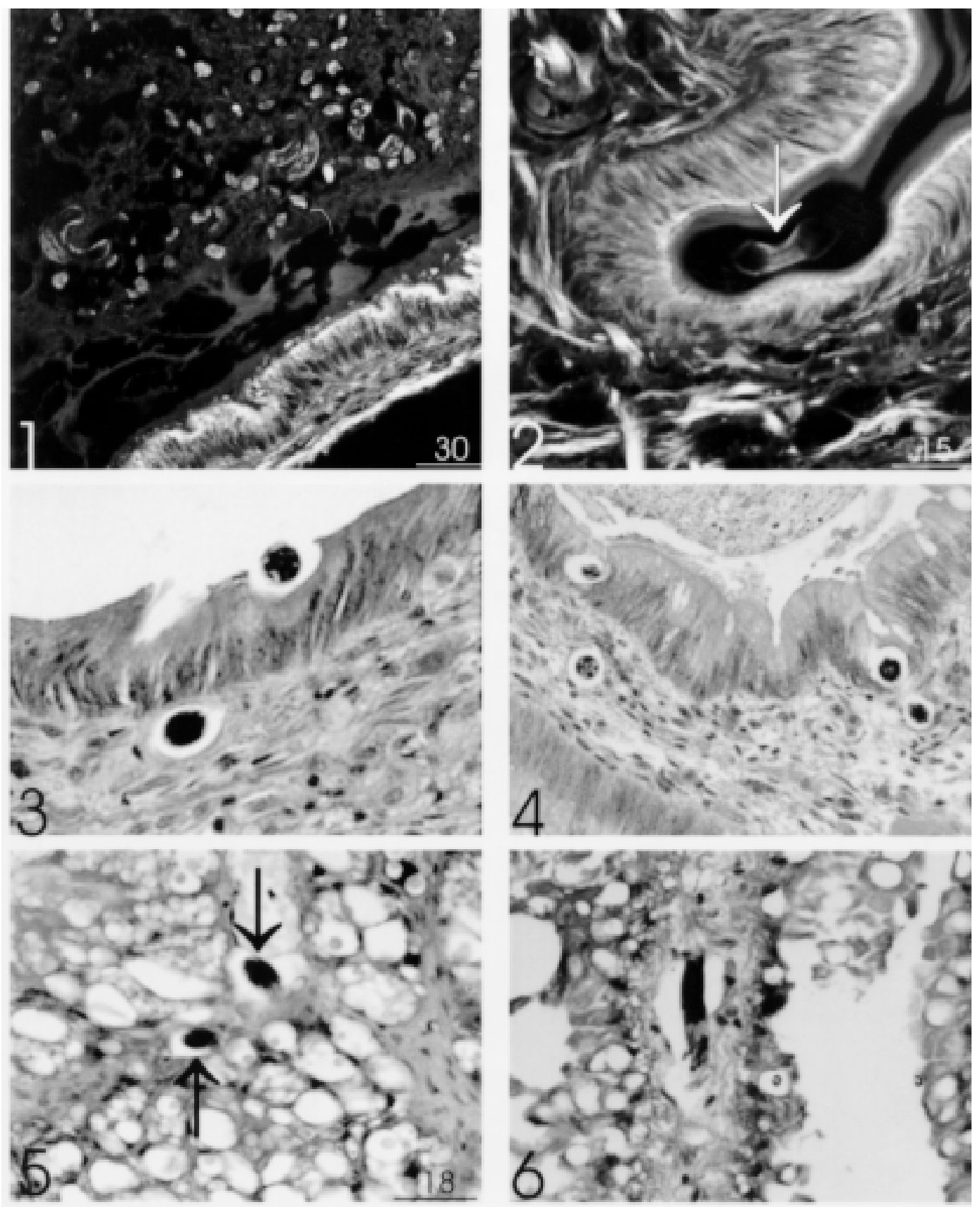

Fig. 1: several $\mathrm{L}_{1}$ in the lumen of stomach (time of infection: $\left.30 \mathrm{~min}\right)(\mathrm{HE}-\mathrm{CLSM}$ reflected mode. Bar $=30 \mu \mathrm{m})$. Fig. $2:$ larva $\left(\mathrm{L}_{1}\right)$ (arrow) in contact with bulb buccal epithelium, producing depression in its surface and thinning of the cuticular layer (time of infection: $30 \mathrm{~min}$ ) (HE - CLSM reflected mode. Bar $=15 \mu \mathrm{m}$ ). Fig. 3: stomach showing one $\mathrm{L}_{1}$ on the initial phase of penetration in the epithelium, and another one in the interstice, just below the basement membrane (time of infection: 2 hr) (HE, 640x). Fig. 4: intestine showing $\mathrm{L}_{1}$ on final phase of intraepithelial penetration (supra-basement membrane location) and in the subepithelial connective tissue (time of infection: $2 \mathrm{hr}$ ) (HE, 400x). Fig. 5: larvae $\left(\mathrm{L}_{1}\right)$ in the digestive gland (arrows) (time of infection: $1 \mathrm{hr}$ ) $(\mathrm{HE}, \mathrm{CLSM}$. Bar $=18 \mu \mathrm{m})$. Fig. 6: larvae $\left(\mathrm{L}_{1}\right)$ in the interstice of kidney with few contiguous amebocytes (time of infection: $8 \mathrm{hr}$ ) (HE-500x). 
Independently of the penetration sites, $\mathrm{L}_{1}$ showed a tendency to migrate to the fibromuscular layer where they moulted from $\mathrm{L}_{1} \rightarrow \mathrm{L}_{2} \rightarrow \mathrm{L}_{3}$. The fibromuscular layer differentiates from the rest of the
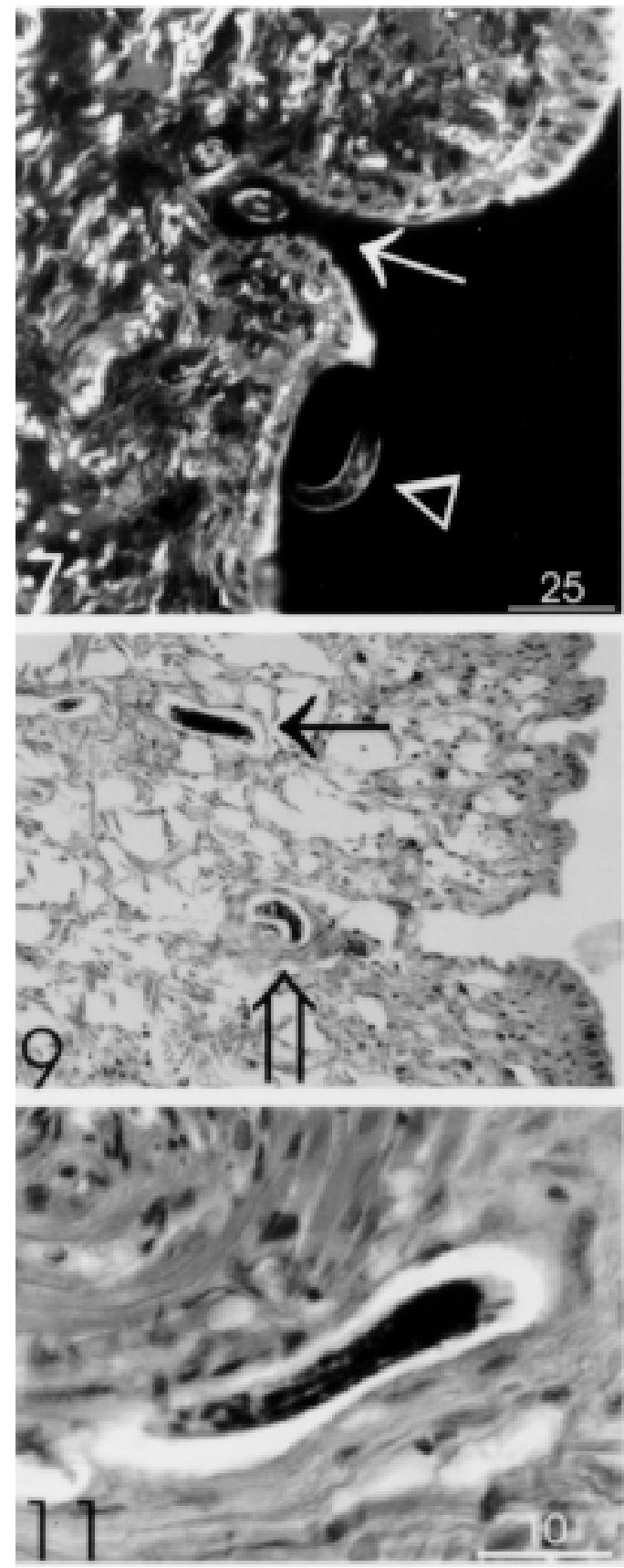

organism due to considerable vascularity, vigorous fibromuscular tissue, intense innervation and abundant secretory glands. Probably the fibromuscular layer represents a complex microenviron-
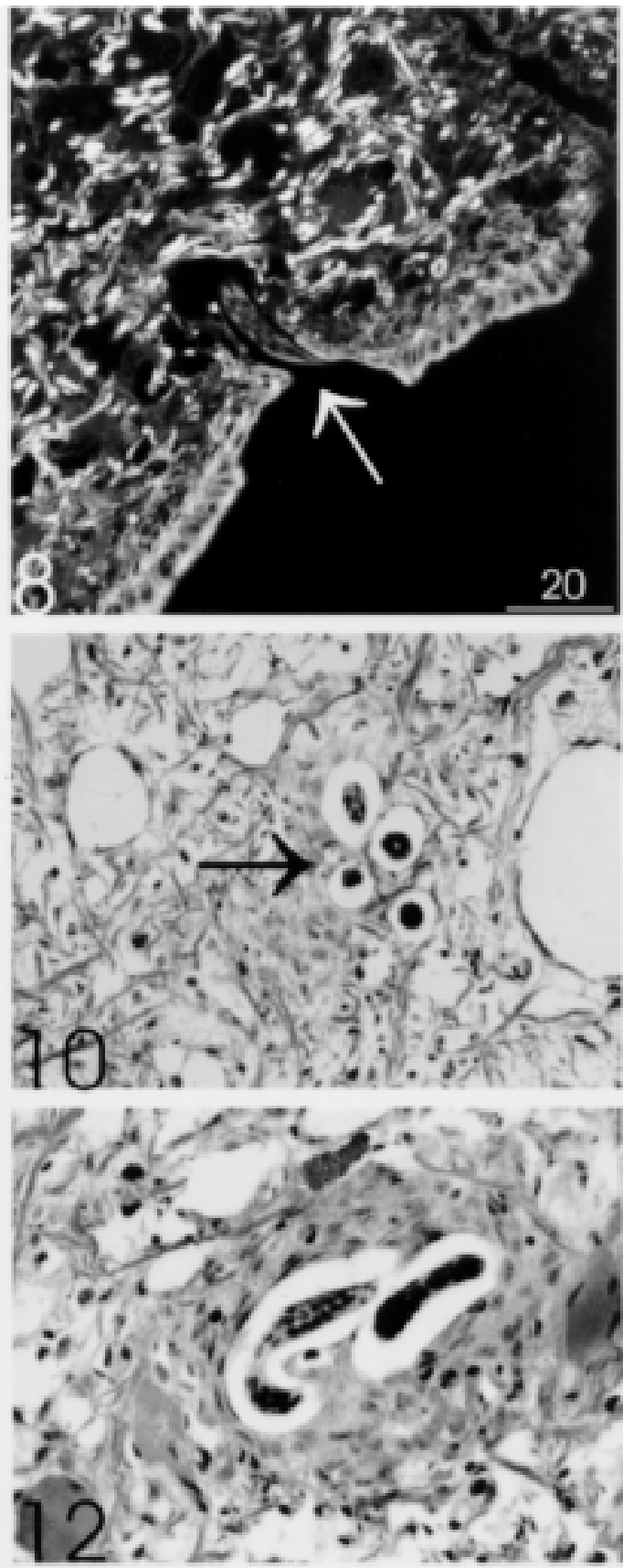

Figs 7, 8: larvae $\left(\mathrm{L}_{1}\right)$ near the tegumental epithelium (head of arrow) and inside excretory ducts of mucous glands (arrow) (time of infection: $30 \mathrm{~min}$ ) HE, CLSM. Bar $=25 \mu \mathrm{m}$ (Fig. 7), Bar $=20 \mu \mathrm{m}$ (Fig. 8). Fig. 9: larvae in the fibromuscular layer, one of them near an excretory duct presenting initial phase of perilarval reaction (double arrow) and another one free of reaction (arrow) (time of infection: $6 \mathrm{hr}$ ) (HE, 260X). Fig. 10: larvae in the fibromuscular layer (arrow), partially surrounded by amebocytes and next to hemolymph vessels (time of infection: $6 \mathrm{hr}$ ) (HE, 400x). Fig. 11: larva in the fibromuscular layer partially surrounded by a monolayer of amebocytes, some of them showing spindle nuclei similar to fibroblasts (fibroblast-like cells) (time of infection: $2 \mathrm{hr}$ ) HE, CSLM. Bar $=10 \mu \mathrm{m}$. Fig. 12: two larvae in the fibromuscular layer, surrounded by several layers of amebocytes (pre-granulomatous reaction) near superficial vessels (time of infection: $6 \mathrm{hr}$ ) (HE, 500x). 
ment, which is suitable to larval homing (ecotaxy) and moult. Indeed, the majority of the larvae was found at this level.

The migration of $\mathrm{L}_{1}$ and $\mathrm{L}_{3}$ is an active process involving larva movements, which appears to be associated with the participation of proteolytic enzymes. This phenomenon is apparently exem- plified by the presence of an empty perilarval space, even around the immobile $\mathrm{L}_{2}$ (Figs 3-6, 20).

The larva invasion of several viscera occurs by migration across organ to organ or through anatomophysiological ducts, coeloma or body cavity. The invaded organs operate as intermediate steps (or way of passage) to the larvae before reaching the final
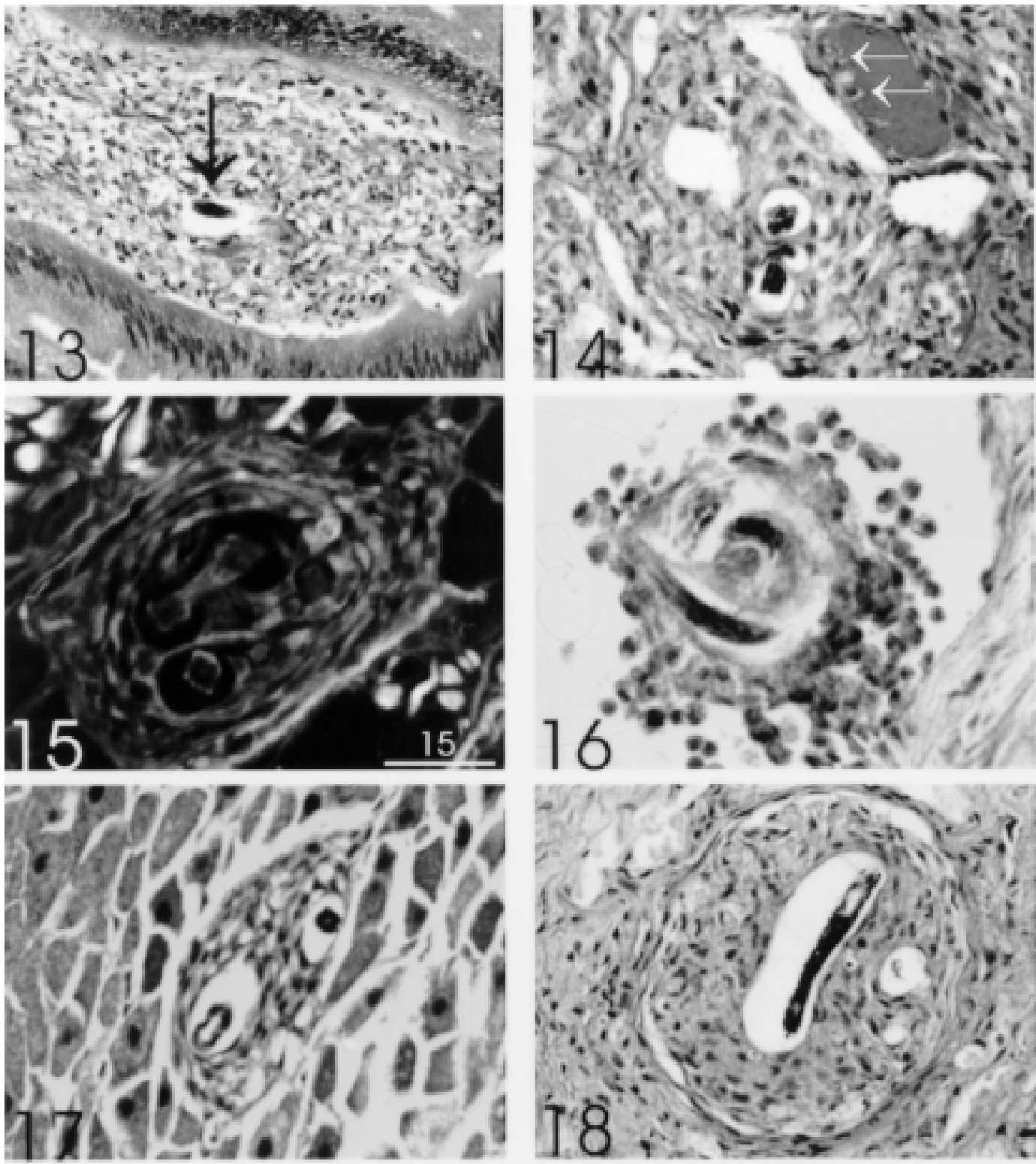

Fig. 13: non organoid scattered reaction of amebocytes around $\mathrm{L}_{1}$ (arrow) in subepthelial connective tissue of copulation purse (time of infection: $8 \mathrm{hr}$ ) (HE, 310x). Fig. 14: pre-granulomatous reaction around $\mathrm{L}_{1}$ in the periphery of the fibromuscular layer near to a superficial vessel, which presents amebocytes sticked to the endothelium (arrows) side that looks on to perilarval reaction (time of infection: $8 \mathrm{hr}$ ) (HE, 500x). Fig. 15: pre-granulomatous perilarval reaction in the fibromuscular layer without evidence of collagen fibers within it (time of infection: $24 \mathrm{hr}$ ) PMA-PS, CLSM. Bar $=15 \mu \mathrm{m}$. Fig. 16: intravascular perilarval reaction showing centripetal gradient of celular adhesion (time of infection: $24 \mathrm{hr}$ ) (HE, 500x). Fig. 17: pre-granulomatous perilarval reaction in the interior of pedial gland showing fibroblast-like amebocytes (time of infection: 2 days) (HE, 500x). Fig. 18: perilarval granuloma $\left(\mathrm{L}_{2}\right)$ presenting two well defined strata: the internum, bearing epithelioid amebocytes, and the externum thinner, which forms a pseudo-capsule constituted by fibroblast-like cells (time of infection: 5 days) (HE, 310x). 
habitat, the fibromuscular layer. The kidney appears to provide the main passage way for orally delivered larvae to reach the fibromuscular layer. In fact, this organ was found to be parasited in all slugs in significant amounts when compared with other organs. Contigently, some larvae are arrested inside the viscera by the inflammatory reaction (Figs 13, 17). However, as in vertebrates, the inflammation predominates in the fibromuscular layer which is intensely vascularized. The amebocytes, within the
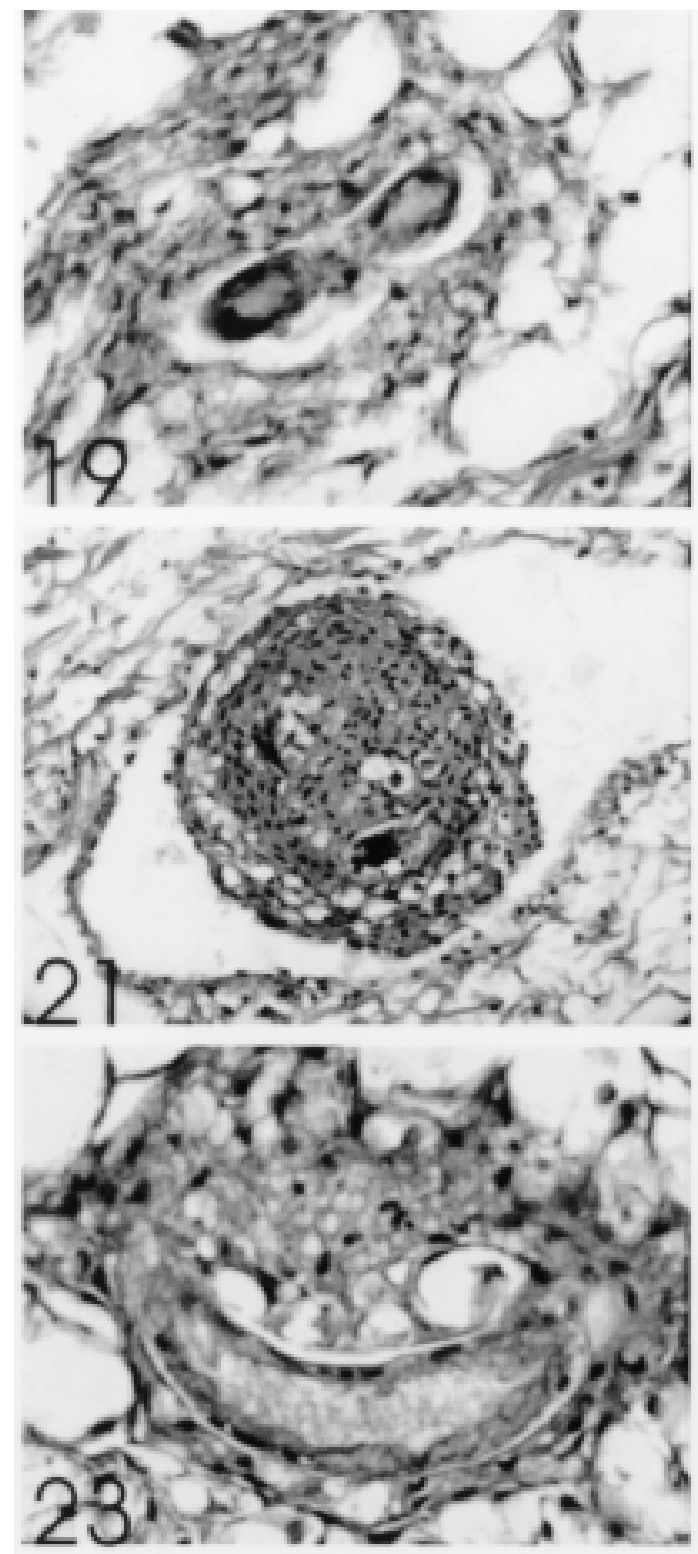

vessels, showed margination and increased adhesiveness and sticking to the endothelial cells, pointing out to the phylogenetic precocity of this capital event of the inflammatory process (Figs 14, 24). Amebocytes also stick to each other, revealing that the surface changes are not limited to the endothelium (Figs 16, 20, 24).

Larvae that have penetrated by tegumental or percutaneous infection got immediate access to the fibromuscular layer, where there is a network of
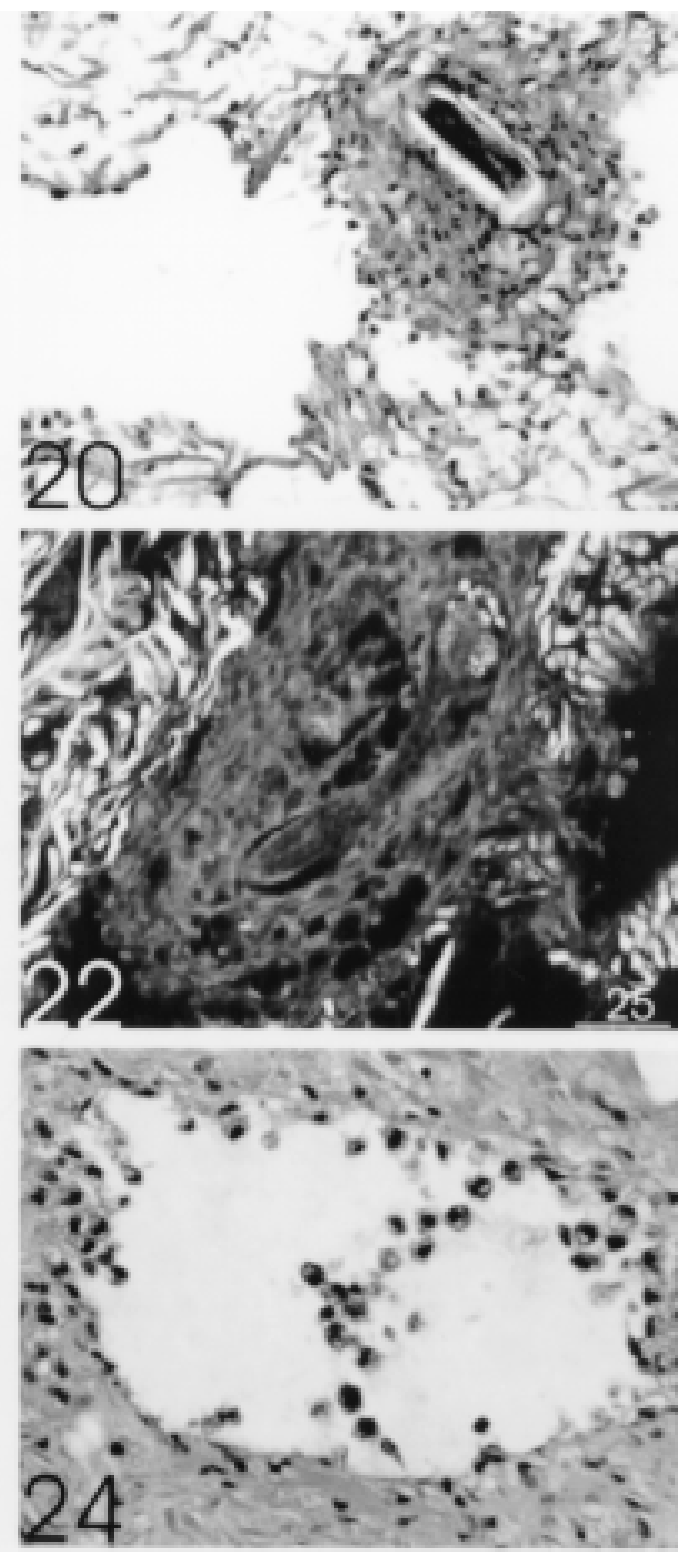

Fig. 19: vacuolate amebocytes surrounding transitional larvae $\left(\mathrm{L}_{2}-\mathrm{L}_{3}\right)$ (time of infection: 8 days) (HE, 500x). Figs 20, 21: intravascular granulomas surrounding $\mathrm{L}_{3}$ in dilated hemolymph vessels (time of infection: 30 days) (HE, 260x). Fig. 22: absence of collagen in perilarval granuloma $\left(\mathrm{L}_{3}\right)$ (time of infection: 30 days) (PMA-PS, CLSM. Bar $\left.=25 \mu \mathrm{m}\right)$. Fig. 23: larva $\left(\mathrm{L}_{3}\right)$ eccentrically surrounded by intensely vacuolate amebocytes (time of infection: 30 days) (HE, 500x). Fig. 24: hemolymph vessel presenting large number of amebocytes marginally sticked to the endothelium or forming clusters (time of infection: 5 days) (HE, 400x). 
subepithelial vessels which facilitates the amebocyte migration, provoking rapid amebocytic encapsulation around larvae. This event made possible to discriminate the larvae originated from each route of infection. For instance, comparing the perilarval reaction in Fig. 6 ( $8 \mathrm{hr}$ of oral infection), with Fig. 10 (6 hr of percutaneous infection) it is possible to observe almost absent or minimal intrarenal perilarval reaction in the former (oral infection), and large amount of amebocytes in the latter, surrounding intra-fibromuscular larvae (percutaneous infection).

The amebocyte reaction around invaded parasites has been considered in the literature as an encapsulating phenomenon (Pan 1965, Richards \& Merritt 1967, Cheng \& Rifkin 1970, Harris 1975, Harris \& Cheng 1975, Lie \& Heyneman 1975, Rachford 1976, Krupa et al. 1977), or as a collection of amebocytes (Conejo \& Morera 1988), or as a granulomatous structure (Pan 1965, Souza et al. 1995, 1997). In this work we considered the very well developed perilarval reaction as typical granulomas, mainly when there was formation of epithelioid cells (Fig. 18). The granulomas were constituted by compact or organized collection of amebocytes showing, sometimes, the definition of two strata. The granulomatous stage was preceded by mobilization and aggregation of amebocytes around larvae (pre-granulomatous stage) (Fig. 16). Multinucleated or giant cells were never detected in the granulomas, confirming similar observation made by Pan (1965) in Australorbis glabratus infected with Schistosoma mansoni. After 30 days of infection, most of the larvae were located within vessels, evidencing, even in invertebrate host, the preference of Angiostrongylidae for intravascular habitat. During this period, and sometimes earlier, intravascular pre-granulomatous reaction or granulomas formed free (Fig. 16) or trapped (Figs 20, 21) emboli, causing vascular dilatation due to blockage of hemolymph circulation. Pan (1965), in S. mansoni infected A. glabratus, also observed, during the period of heavy emergence of cercariae, intravascular infiltration of hipertrophyc amebocytes around them, forming "cercarial emboli".

We did not detect presence of interstitial collagen in the granulomas (Figs 15, 22), reinforcing the assumption that the fibroblastic-like cells are flattened amebocytes (Sminia et al. 1974, Harris 1975, Cheng \& Garrabrant 1977, Locker 1979), instead of fibroblast or myofibroblast. Granulomas in S. marginata, at least during the period of this experiment, appears not to kill the larvae and may even contribute to the process of larval moulting. Harris and Cheng (1975) also observed that $A$. cantonensis larvae are not destroyed by Biomphalaria glabrata amebocytes, and, on the con- trary, they successfully complete their metamorphosis despite rapid encapsulation which give a strong staining reaction for acid phosphatase, $\beta$ glucoronidase, and non-specific esterases. Such capsules persist for long periods and viable firststage larvae have been recovered from Biomphalaria up to 12 months after infection (Richards \& Merrit 1967).

According to Conejo and Morera (1988), a rupture produced by muscular contraction is required for $\mathrm{L}_{3}$ evasion of the encapsulating reaction, allowing them to escape from the intermediate host. Then, the fibromuscular layer, besides being the preferred environment for the larval development, independently of $\mathrm{L}_{1}$ portal of entry, it also favours the larvae extrusion due to muscular contraction. This is another example in the literature that shows exploitation of the host response by the parasite, aiming at continuing its life cycle (Damian 1987, Lenzi et al. 1997).

Histological observations, without quantitative analysis, suggest that there is an increased number of circulating amebocytes (hemocytosis) in the infected $S$. marginata. The mesothelial lining of the pericardial coeloma appears to be the main source of $S$. marginata amebocytes (coelomocytes), as it was suggested by the observations of serial sections (data not shown). Bilej et al. (1992) found that, in stimulated earthworms by infecting arsanilic acid coupled to human serum albumin in 3\% agar gel (ARS-HSA), the cells of the lining of the coelomic cavity respond immediately to stimulation as measured by $\left[{ }_{3} \mathrm{H}\right] \mathrm{TdR}$ uptake, indicating mitotic activity of coelomocytes.

In conclusion, this paper shows that $A$. costaricensis infection in $S$. marginata provokes systemic amebocyte mobilization (hemocytosis) and perilarval granulomatous reaction, with participation of epithelioid cells. It emphasizes the concept that the granuloma is intrinsically a macrophage phenomenon, phylogenetic ancient, that prescinds from $B$ and $T$ lymphocytes. It operates as hybrid interface (composed by host and parasite components) between two different phylogenetic beings, which try to favour a symbiotic cohabitation between them.

\section{ACKNOWLEDGEMENTS}

To AL de Amorim, FF Cruz, ID Pedro (Department of Pathology, Instituto Oswaldo Cruz) for their technical assistance.

\section{REFERENCES}

Bilej M, Sima P, Slipka J 1992. Repeated antigenic challenge induces earthworm coelomocyte proliferation. Immunol Lett 32: 181-184.

Carson FL, Martin JH, Lynn JA 1973. Formalin fixation for electron microscopy: a re-evaluation. $\mathrm{Am} \mathrm{J}$ 
Clin Pathol 59: 365-375.

Cheng TC, Garrabrant TA 1977. Acid phosphatase in granulocytic capsules formed in strains of Biomphalaria glabrata totally and partially resistant to Schistosoma mansoni. Int J Parasitol 7: 467-472.

Cheng TC, Rifkin E 1970. Cellular reactions in marine molluscs in response to helminth parasites. Amer Fish Soc Søec Publ 5: 443-496.

Conejo ME, Morera P 1988. Influência de la edad de los veronicelideos en la infección con Angiostrongylus costaricensis. Rev Biol trop (S. José) 36 (2B): 519-526.

Damian RT 1987. The exploitation of host immune responses by parasites. J Parasitol 73: 3-13.

Dolber PC, Spach MS 1993. Conventional and confocal fluorescence microscopy of collagen fibers in the heart. J Histochem Cytochem 41: 465-469.

Duarte Z, Morera P, Davila P, Gantier JC 1992. Angiostrongylus costaricensis natural infection in Vaginulus plebeius in Nicaragua. Ann Parasitol Hum Comp 67: 94-96.

Graeff-Teixeira C, Thiengo SC, Thomé JW, Medeiros AB, Camilo-Coura L, Agostini AA 1993. On the diversity of mollusc intermediate hosts of Angiostrongylus costaricensis Morera \& Cespedes, 1971 in southern Brazil. Mem Inst Oswaldo Cruz 88: 487-489.

Graeff-Teixeira C, Thomé JW, Pinto SCC, CamilloCoura L, Lenzi HL 1989. Phyllocaulis variegatus an intermediate host of Angiostrongylus costaricensis in South Brazil. Mem Inst Oswaldo Cruz 84: 65-68.

Harris KR 1975. The fine structure of encapsulation in Biomphalaria glabrata. Ann NY Acad Sci 266: 446464.

Harris KR, Cheng TC 1975. The encapsulation process in Biomphalaria glabrata experimentally infected with the metastrongylid Angiostrongylus cantonensis: Light microscopy. Int J Parasitol 5: 521.

Kaminsky RG, Andrrews K, Mor NR 1987. Angiostrongylus costaricensis en babosas en Honduras. Estudo preliminar. Rev Méd Hond 55: 4-8.

Krupa PL, Lewis LM, Del Vecchio 1977. Schistosoma haematobium in Bulinus guernei: electron microscopy of hemocyte-sporocyst interactions. J Invertebr Pathol 30: 35.

Lenzi HL, Pacheco RG, Pelajo-Machado M, Panasco MS, Romanha WS, Lenzi JA 1997. Immunological system and Schistosoma mansoni: co-evolutionary immunobiology. What is the eosinophil role in parasite-host relationship? Mem Inst Oswaldo Cruz 92 (Suppl. II): 19-32.

Lie KJ, Heyneman D 1975. Studies on resistance in snails: a specific tissue reaction to Echinostoma lindoense in Biomphalaria glarata snails. Int $J$
Parasitol 5:621.

Loker ES 1979. Pathology and host responses induced by Schistosomatium douthitti in the freshwater snail Lymnaea catascopium. J Invert Pathol 33: 265-273.

Morera P 1973. Life history and redescription of Angiostrongylus costaricencis Morera and Céspedes, 1971. Am J Trop Med Hyg 22: 613-621.

Morera P, Ash LR 1970. Investigacion del huesped intermediario de Angiostrongylus costaricensis (Morera y Céspedes, 1971). Bol Chileno Parasitol 25: 135 .

Morera P, Céspedes R 1971. Angiostrongilosis abdominal. Una nueva parasitosis humana. Acta Med Costa 14: 159-173.

Morera P, Andrews KL, Rueda D 1988. The intermediate host Angiostrongylus costaricensis in Honduras. Rev biol Trop 36: 575-576.

Morera P, Lazo R, Urquizo J, Laguno M 1983. First record of Angiostrongylus costaricensis Morera and Céspedes, 1971 in Ecuador. Am J Trop Med Hyg 32: 1460-1461.

Pan CT 1965. Studies on the host-parasite relationship between Schistosoma mansoni and the snail Australorbis glabratus. Am J Trop Med Hyg. 14: 931976.

Rachford FW 1976. Host-parasite relationship of Angiostrongylus cantonensis in Lymnaea palustris. II. Histopathology. Exp Parasitol 39: 382.

Rambo RP, Agostini AA, Graeff-Teixeira C 1997. Abdominal angiostrongylosis in southern Brazil - prevalence and parasitic burden in mollusc intermediate host from eighteen endemic foci. Mem Inst Oswaldo Cruz 92: 9-14.

Richards CS, Merritt JW 1967. Studies on Angiostrongylus cantonensis in molluscan intermediate hosts. J Parasitol 53: 382.

Sminia T, Borghart-Reinders E, van de Linde AW 1974. Encapsulation of foreign materials experimentally introduced into the freshwater snail Lymnaea stagnalis. Cell Tiss Res 153: 307-326.

Souza CP, Borges CC, Santana AG, Andrade ZA 1995. Comparative histopathology of Biomphalaria glabrata, B. tenagolphila and B. straminea with variable degrees of resistance to Schistosoma mansoni miracidia. Mem Inst Oswaldo Cruz 92: 517-522.

Souza CP, Cunha RCP, Andrade ZA 1997. Development of Biomphalaria tenagophila, Biomphalaria straminea and Biomphalaria glabrata. Rev Inst Med Trop 37: 201-206.

Thiengo SC 1996. Mode of infection Sarasinula marginata (Mollusca) with larvae of Angiostrongylus costaricensis (Nematoda). Mem Inst Oswaldo Cruz 97: 277-278. 